\title{
Regional segregation or industrial monopoly? Dual labor market segmentation and income inequality in China
}

Yaqiang $\mathrm{Qi}^{1^{*} \text { (D) and Tongxin Liang }}{ }^{2}$

* Correspondence: qiyaqiang@ruc.edu.cn ${ }^{1}$ Department of Sociology, Renmin University of China, No.59

Zhongguancun Street, Haidian District, Beijing 100872, China Full list of author information is available at the end of the article

\begin{abstract}
Using data from the 2010 China Family Panel Study and county- and industry-level statistics, we estimate cross-classified multilevel models to examine the determinants of the income gap among Chinese workers. Results show that both regional and industrial differences are important sources of income inequality in China. Taken together, they account for about one fifth of the total variation in individual income. Among them, differences in county explains $7 \%$, while difference in industry accounts for $14 \%$ of the total variation. Further analyses demonstrate that county- and industry-level variables have significant independent effects on individual income even after controlling for individual socio-demographic characteristics and human capital resources. We also explore the potential mechanisms through which macro-level factors function in widening income gaps among Chinese workers. Our results show industrial monopolies have been a key driver of the elevated income inequality in China.
\end{abstract}

Keywords: Income inequality, Income distribution, Labor market segmentation, Regional segregation, Industrial monopoly

\section{Introduction}

China witnessed rapid economic growth and great alleviation of poverty since its economic reform. However, China's income gap widened substantially at the same time, and income inequality has become a major threat to sustainable economic development and continuous improvement in living standards. Recent social surveys prove that income inequality is regarded as the leading social problem facing contemporary China, ahead of all other critical challenges such as corruption, unemployment, and environmental pollution (see Xie et al. 2013: 349). Therefore, it is essential that social scientists explore the underlying mechanisms through which income distribution is determined in China, especially the social and institutional factors that drive the level of inequality.

There is a growing body of literature that focuses on the rising income inequality in China that has occurred during the reform era, which suggests that China has been transformed from a relatively egalitarian society into a society with significant income gaps over the past several decades. ${ }^{1}$ These studies suggest that market transition and

(c) The Author(s). 2016 Open Access This article is distributed under the terms of the Creative Commons Attribution 4.0 International License (http://creativecommons.org/licenses/by/4.0/), which permits unrestricted use, distribution, and reproduction in any medium, provided you give appropriate credit to the original author(s) and the source, provide a link to the Creative Commons license, and indicate if changes were made. 
institutional barriers play important roles in the dramatic change, with rural-urban segregation, sector variation, and regional and industrial differences identified as the leading structural causes for the unequal distribution of income. Nevertheless, to date, previous studies on this topic remain fragmented in that it is rare for the previously mentioned factors to be synthesized within a unified framework or to be examined simultaneously. As a result, our knowledge regarding how social mechanisms affect income inequality as well as the relative contribution of different factors is still limited in terms of both theory building and empirical evidence.

In this study, we base our investigation on an extended labor market segmentation theory and empirically examine how different structural and institutional factors contribute to the elevated income inequality in China. In particular, we pay special attention to the relative roles that regional segregation and industrial monopoly play in the determination of individual income by fitting cross-classified multilevel models. Compared with previous studies, this study fills the gap in the literature in three important aspects: First, given the institutional reality of "departmental and regional segregation (tiao kuai fenge)" in the Chinese governance system, we simultaneously consider industry and regional factors, creating a cross-classified framework of labor markets. This enables us to disentangle the independent effects of different contextual factors affecting income inequality. Furthermore, within this general framework, we also consider other social and structural factors such as gender, residence type, education, political capital, occupation, and work unit. By doing so, we provide one of the most comprehensive examinations of China's income inequality issue to date. Second, we depart from previous studies by including both urban and rural residents in our analysis instead of only focusing on urban samples. This is because rural-urban differences account for a large proportion of the total inequality in China, and it is highly likely that we underestimate the level of inequality and even produce misleading results if we exclude rural samples. Third, compared with other studies on regional variations of income, we use county as our unit of analysis rather than province or city. By focusing on a smaller and relatively homogeneous regional unit, it is likely that we can better capture regional variations and more precisely estimate the effect of regional barriers on individual income.

\section{Literature review and research design}

Market transition, labor market segmentation, and income inequality

The study of inequality has always constituted a core of sociology. Different from classical economic theory, which views wages or income as the price of human capital (such as skills and work experiences) in the labor market, and which are in turn determined by the supply and demand forces of market competition, sociological theory generally emphasizes the socio-structural and institutional facets of income determination. In particular, labor market segmentation theory argues that labor markets are never a perfect competitive market as portrayed by classical economic theory, but instead are always embedded in other social institutions and specific social arrangements. According to this theory, the labor market in modern societies is usually segregated into two relatively isolated parts: the primary market and the secondary market. They correspond to the core sector and the peripheral sector of the economic industry, 
respectively (Beck et al. 1978). In the primary labor market, jobs are generally well paid and well protected, the working environment is superior, and there are more opportunities for promotion. By contrast, in the secondary labor market, jobs are often underpaid, less secure, and with little opportunity for career advancement (Cain 1976; Kalleberg and Sorensen 1979). In short, labor market segmentation theory indicates that earnings are not simply determined by individual stock of human capital and market competition, and therefore, it is important to examine the contextual and institutional forces in order to fully understand income inequality in a given society.

With respect to China, the labor market was essentially non-existent before the reform era. Under the central planning and redistributive economy system, individual income was mainly determined by one's work unit and its relevant ranking in the redistribution sequence. In general, people who work in state-owned enterprises, especially in those work units with higher administrative ranking, earn more. Within a given work unit, income is relatively equally distributed among its workers (Walder 1992). Beginning with marketization reform, China's labor market has formed gradually, which in turn has led to dramatic changes to income distribution and the overall economic structure in China (Bian and Zhang 2002; Liu 2006).

The market transition has been the focus of theoretical debates and empirical investigations regarding income distribution in China. According to market transition theory (Nee 1989), due to systematic differences in income determination between a market economy and a redistributive economy, marketization will necessarily increase income returns from human capital and depreciate the value of political capital at the same time. Following this proposition, many studies have focused on the diversifying effect of market reform on individual income under the framework of state vs. market (Bian and Logan 1996; Zhou 2000). These studies show that the income distribution system varies over time and has substantial between-sector differences. Although marketization leads to significant increase of income returns from human capital, political capital remains an important determinant of income in China, especially within state-owned sector (Zang 2002; Zhou 2000). Compared with state-owned sector, human capital receives higher rewards from the private sector. Nonetheless, the pace of income growth has been very rapid in stateowned sector in recent years, which has regained its earnings advantage over the private sector (Bian and Zhang 2002).

Although previous studies suggest that sector variation is a critical source of income inequality in China, the simple dichotomous classification of state and market sectors is far from adequate for understanding the pattern of income distribution in contemporary China. In addition to ownership differences, there is substantial income variation across different regions, industries, as well as work units (Wang and Wang 2005). Wang and Wang (2005) emphasize that various collective social groups play a critical role in determining income distribution in China. During the process of market transition, to maintain their collective interests, relevant social groups take advantage of the inherited influences from the old central planning system and seek to maximize collective benefits. Within each social group, income tends to be distributed relatively equally among its members. As a result, income inequality can rapidly widen between social groups while remaining relatively stable within groups. Their empirical investigation shows that differences across regions, industries, and ownership types are important sources of income inequality, and they together account for about half of the total 
variation in individual income in China. In particular, the impact of regional and industrial variation on individual income is rising rapidly. In addition, there are also studies that examine labor market segmentation in terms of gender (Deng and Ding 2012), hukou type ( $\mathrm{Li}$ and $\mathrm{Gu} 2011$ ), and occupational status (Wu 2011), indicating the complex and multiplistic nature of labor market segmentation in Chinese society.

Overall, these previous studies imply that the underlying social mechanisms that determine income distribution are quite complicated, and it is insufficient to simply apply the state vs. market perspective to explain changes in income distribution in China following marketization reform. In fact, administrative power and market power have often been intertwined during the process of market transition in China, and they together determine the structural characteristics of sector segregation, distributions of various resources, labor market conditions, and consequently the level of income inequality. Therefore, we need to develop a more comprehensive analytical framework to effectively understand the process of income determination in China. In the following, based on the institutional arrangement of "departmental and regional segregation (tiao kuai fenge)" of the Chinese governance system, we argue that industry and region form a dual segmentation of the labor market, together constituting the basic structure of income determination in China. Industry and region segmentation, jointly with other social forces such as gender, residence type, occupation, and work unit, together construct a complex picture of income distribution in contemporary China.

\section{Industrial monopoly and income inequality}

Among the many factors affecting income distribution, variations in income by industry has received much attention, especially in the economic literature. Statistical data show that income gaps across different industries have been substantial during the reform era, rising continuously since the late 1980s (Cai et al. 2005; Gu and Feng 2008). As a result, the relative contribution of inter-industry variation to the total variation in income has also increased dramatically (Chen et al. 2010).

As a matter of fact, income variation by industry is common in modern societies. Many studies attribute this phenomenon to different compositions of human capital across industries (e.g., Dickens and Katz 1987; Krueger and Summers 1988). Due to the nature of work, industries differ in their required skill levels and their investment in human capital, which can lead to different levels of average rewards being received by industry workers. Nonetheless, the human capital differential alone cannot explain the observed inter-industry variations in income, and there still exist persistent income gaps across industries even after controlling for different human capital compositions (Katz et al. 1989).

With respect to inter-industry income inequality in transitional China, many studies attend to the special role that state power plays in the process of market transition. These studies suggest that the substantial income gaps that exist across different industries are primarily due to industrial monopoly, endorsed by administrative power. For instance, Luo and Li (2007) report that although human capital, capital investment, production scale, and amount of revenue all have significant effects on average industrial income, they together only account for a small portion of income variation by industry. In contrast, the power that arises from being a monopoly plays a more 
important role in forming inter-industry income gaps (Ren and Zhou 2009; Zhang and Chen 2008). Monopolized industries in general have much higher average income than other industries; the higher income is mainly from the result of administrative monopoly rather than naturally occurring market monopoly. Based on a decomposition of the higher income observed in monopolized industries, Yue et al. (2010) find that at least half of the income gap between monopolized and other industries cannot be justified by market forces, but instead mainly comes from administrative monopoly endorsed by governmental power.

These previous studies illustrate the importance of industry segmentation on income inequality in China, but due to issues such as data availability, there still exist two key limitations in the current literature. First, industrial monopoly has been singled out as one of the main forces affecting income inequality across industries; however, monopolized industries differ from other industries in many other important aspects. For example, monopolized industries tend to have more human capital stock (Zhang 2004), and knowledge, skills, and financial capital are also more concentrated in these industries, which may speed up technological innovation, improve productive efficiency, and thus increase human capital returns. Hence, to precisely estimate the impact of monopoly on income variations by industry, industrial characteristics should be analyzed more systematically. Second, as a structural factor of the labor market, industry not only affects average employee income, but also greatly influences income distribution for individuals having different characteristics. However, with one exception (Wang and Cui 2010), there is essentially no study that explores the macro-micro interactions between industry and individual characteristics with respect to income determination. As a result, we still know little about the specific mechanisms through which individual income is affected by industry segregation.

\section{Regional segregation and income inequality}

The above discussion about inter-industry income gaps presupposes that there is a unified national labor market. However, in reality, this hypothetical national labor market rarely exists. Regional variation has always been a special feature of China's economic development and institutional change (Walder 1995; Xie and Hannum 1996). Due to differences in culture, environment, resources, as well as specific governmental policies, there are wide variations in terms of social and economic development across China's different regions. In particular, the strong push to protect local interests and associated institutional barriers (e.g., the hukou system) hamper the formation of a unified national labor market; as a result, local labor markets are relatively segregated and closed to each other. In fact, market competition has not yet been able to equalize income returns for all local markets, and it is crucial to simultaneously take into account regional segregation when we study the industry segregation of income.

China's market transition is a gradual process. Industry compositions and labor market conditions vary substantially across different regions due to differences in development strategies, sector structures, and levels of economic maturity. Many studies show that regional characteristics are important determinants of individual income in urban China (Bian and Zhang 2002; Hao and Li 2006; Xie and Hannum 1996). Moreover, studies also show that the income determination mechanism differs greatly across 
regions. For instance, Liu and Qu's study (2008) indicates that, although industrial enterprises have higher wage levels in both Beijing and Jiangsu and Zhejiang provinces, the underlying mechanisms differ. In Jiangsu and Zhejiang, the higher wages are mainly due to higher production efficiency and better human capital returns led by an effective labor market and sufficient labor mobility among different sectors and industries. By contrast, Beijing's high wages are more closely associated with industrial monopoly and administrative barriers, all of which leads to higher corporate profits through rentseeking behaviors. In short, regional heterogeneity cannot be neglected if we are to fully understand China's income distribution.

In addition, there are also studies that examine the impact of the hukou system, local protectionism, and employment discrimination against outsiders on local labor market outcomes. These studies show that rural-to-urban migrants and urban native residents are segregated in terms of sector entrance, industry entrance, and occupational attainment (Meng and Zhang 2001; Wang et al. 2002). This kind of labor market segmentation exists not only between agricultural and non-agricultural hukou holders, but also between migrants and natives more generally (Guo and Zhang 2012; Li and Gu 2011). To a certain extent, regional segregation is replacing the rural-urban divide to become the main facet of labor market segmentation in China (Zhang 2007). This regional segregation, together and intertwined with segregations by sector, industry, and occupation, constitutes the basic structure of China's labor market and the resulting income inequality.

\section{Research design}

As discussed above, the labor market in contemporary China is simultaneously segregated by multiple structural and institutional factors. They tend to overlap and intertwine with each other to determine the pattern of income distribution in transitional China. Therefore, it is insufficient or even misleading to simply talk about region or industry segregation of income alone. In this study, by taking into account the institutional arrangement of "departmental and regional segregation (tiao kuai fenge)", we examine the simultaneous impact of region and industry segregation on income inequality. By doing so, we are able to distinguish the independent effect of industry segregation from region segregation and to better understand the complex impact of labor market segmentation on income inequality in transitional China.

To be more specific, firstly, industry itself creates a natural barrier for the free mobility of laborers. As the saying goes, "Going through different industries is like going through mountains (ge hang ru ge shan)." In modern society, each industry usually requires that its practitioners possess some specialized skills. This means that the acquired skills and accumulated working experiences in one industry cannot be transferred into other industries without certain sunk and transitional costs. When an individual chooses to enter an industry, we often see that his/her subsequent job changes are generally limited within that industry, indicating that inter-industry transition costs may be huge. Moreover, there exist strict entry restrictions for many industries, either due to natural constraints, such as lands and mine resources, or due to state monopolies on key industries that are regarded as an indispensable part to the national interest (basic energies, public infrastructure, public finance, etc.). This is especially true in China, where state intervention plays a much larger role in its economic development than in other countries. According to the national 
development strategy, the value assigned to different industries or sectors, due to specific policy initiatives or goals, will impact their priority in receiving national resources. This practice may further widen inter-industry income gaps through the so-called Matthew effect. All in all, as a structural barrier in the labor market, industry characteristics have an important say in the determination of individual income, and hence are indispensible to our understanding of income inequality in a society.

Second, labor market is also restricted by local borders. This is especially so in China, given its hukou administrative system, regionalized economic development policy, and localized financing and taxation arrangements. To protect its own interests, local governments have a strong motive to adopt and practice local protectionism such as encouraging the development of local enterprises and securing employment for native residents via special policy interventions. This may hamper the formation of a unified national market for commodities and laborers. These decentralized administrative measures taken by local governments further raise barriers and costs for labor mobility across regions and exacerbate regional labor market segmentation. Region segregation and industry segregation overlap and intertwine with each other, and they together lay out the basic institutional arrangement that regulates individual economic behaviors and income returns. Therefore, to examine income inequality more comprehensively, we bring region and industry factors into a unified analytical framework. By simultaneously analyzing the impacts of various region and industry characteristics on individual income, we are able to better understand the relative importance as well as specific mechanisms by which different socio-structural factors affect income inequality in China.

Third, taking as our starting point the dual labor market segmentation by industry and region, we extend our analysis of income inequality by including other important social and structural factors for income determination such as gender, residence type, education, occupation, party membership, and type of work unit. As mentioned above, although a number of studies have examined these factors separately and concluded that they are important sources of income inequality in China, there is essentially no study that has done so systematically using a dual labor market segmentation framework. As a result, some key questions regarding the macro-micro mechanisms generating income inequality have not been addressed adequately. Take gender inequality as an example, can regional economic development have an external effect so as to cause income gaps between males and females to converge? Are female workers less discriminated against in terms of earnings if they work in an industry with a higher proportion of female employees? Our study will shed some light on these important issues.

Based on the above design, our empirical investigations aim to address the following three questions: First, how much do region segregation and industry segregation, taken individually, contribute to the overall income inequality among Chinese residents? Which one plays the major role? Second, can differences in average income across regions and industries be explained away by different compositions of population and human capital, or are they due to the genuine impact of region and industry characteristics? Third, how do region and industry characteristics affect individual income? In other words, what are the main macro-micro linkages that drive income gaps among individuals? 


\section{Data and method}

\section{Data sources}

The main data for this study come from the adult file and county file of the 2010 Chinese Family Panel Study (CFPS). In addition, we also compile a data file for industry characteristics based on published statistics from the 2008 Chinese Economic Census. The CFPS is a nationally representative sampling survey project conducted by the Institute of Social Science Survey at Peking University. The purpose of CFPS is to monitor broad themes in social change including population, economy, health, family, and communities in contemporary China. CFPS2010 is the baseline survey for this panel project. In this survey, 14,608 families and their members were randomly selected and interviewed from 25 provinces in mainland China.

To examine variation in individual income, we restrict our analysis to working-age (16-64) individuals who were employed at the time of the interview. After excluding samples with missing values for key variables, the analytical sample for this study consists of 14,698 individuals. $^{2}$

Sample characteristics and relevant region and industry information are presented in Table 1. As Table 1 shows, the average monthly income is 1306 yuan for this sample,

Table 1 Descriptive statistics for key individual, region, and industry variables

\begin{tabular}{|c|c|c|c|}
\hline Variable & Mean/proportion & Standard deviation & Sample \\
\hline \multicolumn{4}{|l|}{ Individual level } \\
\hline Individual monthly income (yuan) & 1306.124 & 3207.396 & 14,698 \\
\hline Male & $54.5 \%$ & - & 14,698 \\
\hline Urban residents & $43.1 \%$ & - & 14,698 \\
\hline Number of years of schooling & 6.957 & 4.981 & 14,698 \\
\hline Work experience (years) & 28.632 & 13.906 & 14,698 \\
\hline Party membership & $8.2 \%$ & - & 14,698 \\
\hline Occupation's ISEI & 32.884 & 14.562 & 14,698 \\
\hline Work at state/collective sector & $17.5 \%$ & - & 14,698 \\
\hline \multicolumn{4}{|l|}{ Region level } \\
\hline County GDP per capita (10,000 yuan) & 4.428 & 5.360 & 162 \\
\hline County average of years of schooling & 9.139 & 1.477 & 162 \\
\hline \multicolumn{4}{|l|}{ Industry level } \\
\hline \multicolumn{4}{|l|}{ Industry type } \\
\hline Agriculture & $5.3 \%$ & - & 19 \\
\hline Industry and manufacturing & $21.1 \%$ & - & 19 \\
\hline Service and other & $73.7 \%$ & - & 19 \\
\hline Industry age (proportion of entities established after 2000) & .643 & .198 & 19 \\
\hline Industry scale (the log of the number of employees) & 15.796 & 1.081 & 19 \\
\hline Proportion of female employees & .368 & .122 & 19 \\
\hline Proportion of employees with higher education & .389 & .214 & 19 \\
\hline Proportion of entities owned by state ${ }^{a}$ & .082 & .107 & 18 \\
\hline Average revenue per capita $(10,000 \text { yuan })^{a}$ & 40.256 & 35.794 & 18 \\
\hline
\end{tabular}

${ }^{a}$ For the industry of "public administration and social organizations," the relevant statistics are not available. In the following analysis, we replaced the missing values with the sample mean and added a dummy variable indicating this missingness 
and its standard deviation is roughly three times as large as its mean, indicating wide income gaps among these respondents. In this sample, males account for $55 \%$, urban residents account for $43 \%$, and about $8 \%$ of the sample are members of the Communist Party. The average number of years of education is about seven, and the mean occupational score is 33 according to the International Socioeconomic Index (ISEI). Finally, around $18 \%$ of the sample is employed in state/collective sectors. ${ }^{3}$

\section{Method}

The outcome variable for our analysis is individual monthly income, reported by respondents during the interview as their total income the previous month. Following common practice, we rescale the original values of income by a natural log transformation to correct for skewness. ${ }^{4}$ As discussed above, individual income is affected by both micro-level factors such as sociodemographics as well as human and political capital, and macro-level factors such as region and industry characteristics. Therefore, we use a multilevel model to examine these effects simultaneously. Specifically, at the individual level, we estimate a refined human capital model similar to Xie and Hannum (1996), by including respondent's gender, education, work experience and its square term, party membership, as well as an interaction between gender and education. Moreover, we also add respondent's residence type (rural vs. urban), occupation, and type of work unit into the model. At the regional level, county-specific GDP per capita and average years of schooling are included to capture the effects of regional economic and social development, respectively. ${ }^{5}$ Finally, at the industry level, we use indicators similar to Wang and Cui (2010), including industry age, scale, proportion of employees with higher education (junior college and above), and proportion of entities owned by state. In addition, we also include dummy variables for industry type, proportion of female employees, and average revenue per capita. Related information regarding these variables can be found in Table 1 .

With respect to specific model form, we choose to fit cross-classified multilevel models because each individual belongs to a certain county and industry simultaneously, but there is no simple clustering relationship between county and industry. ${ }^{6}$ To determine the degree to which region and industry factors account for variations in individual income, we first estimate a variance components model as follows:

$$
\begin{aligned}
& \log \operatorname{Inc}_{i(j k)}=\beta_{0(j k)}+\varepsilon_{i(j k)} \\
& \beta_{0(j k)}=\eta_{000}+\mu_{0 j}+v_{0 k}
\end{aligned}
$$

Take Eq. (2) into Eq. (1), we get

$$
\log \operatorname{Inc}_{i(j k)}=\eta_{000}+\mu_{0 j}+v_{0 k}+\varepsilon_{i(j k)}
$$

where subscripts $j$ and $k$ indicate the $j$ th region and the $k$ th industry, respectively. Since they are not clustered with one another, Eq. (3) uses a bracket to indicate their parallel relationship. In Eq. (3), $\mu_{0 j}, v_{0 k}$, and $\varepsilon_{i(j k)}$ represent the corresponding residuals of the dependent variable at the region, industry, and individual levels, respectively. The model assumes that $\varepsilon_{i(j k)} \sim N\left(0, \sigma_{0 i}^{2}\right), \mu_{0 j} \sim N\left(0, \sigma_{0 j}^{2}\right)$, and $v_{0 k} \sim N\left(0, \sigma_{0 k}^{2}\right)$. We can decompose the total variations in individual income based on estimates of these parameters. 
After fitting the variance components model, we further add the explanatory variables at the individual, region, and industry levels into the model to examine the corresponding effects. In the end, we also add cross-level interactions between individual characteristics and region/industry factors to explore possible macro-micro linkages to income determination. All the models reported in the following are estimated by the "xtmixed" command in Stata13.0. We also estimate the same models with MLwiN2.26 to check the robustness of the estimating results and find that the estimates are identical to those from Stata.

\section{Main findings}

\section{Segregation by region or industry?}

To examine the degree to which segregation by region and segregation by industry account for income inequality among Chinese workers, we first estimate a variance components model. The results are reported in Table 2.

According to the decomposition in Table 2, we can compute the proportions of the total variation in individual income as explained by region and industry differences, i.e., the intra-class correlations $(\rho)$ of the model. Results show that about $7 \%$ of the total variation in individual income is explained by regional variation, ${ }^{7}$ another $14 \%$ of the total variation is explained by inter-industry difference, ${ }^{8}$ and taken together, more than one fifth $(21 \%)$ of observed income inequality is due to differences in region or industry. These findings indicate that region and industry segregations are important causes of elevated income inequality in China. Moreover, the results also suggest that industry segregation plays a much larger role than does region segregation in explaining individual income gaps, ${ }^{9}$ with the relative contribution of the former being twice as large as the latter.

Our findings are similar to those reported by Luo and Li (2007), whose estimates based on materials from the first economic census in China show that variation by province and industry accounts for about 7 and 17\%, respectively, of the total variation in income in China. Our estimate for industry variation is also highly consistent with

Table 2 Variance components model for individual monthly income (Log), CFPS2010

\begin{tabular}{lc}
\hline Variable & Model 0 \\
\hline Intercept & $6.682^{* * *}$ \\
& $(.259)$ \\
Individual level standard deviation $\left(\sigma_{0 i}\right)$ & 2.511 \\
& $(.015)$ \\
Region level standard deviation $\left(\sigma_{0 j}\right)$ & .729 \\
Industry level standard deviation $\left(\sigma_{0 k}\right)$ & $(.049)$ \\
& 1.060 \\
Intra-class correlation (region) & $(.175)$ \\
Intra-class correlation (industry) & .067 \\
Intra-class correlation (total) & .141 \\
\hline
\end{tabular}

Numbers in brackets are estimated standard errors. The corresponding sample sizes for individual, region, and industry are $14,698,162$, and 19 , respectively

*** $p<.001$ 
Wang and Cui's (2010) 13\%. Nonetheless, our results differ substantially from those of Wang and Wang (2005), whose estimates based on a decomposition of the Theil index suggest that the impact of regional variation on income inequality is much more important than that of industry variation. This inconsistency may be caused by their incomplete data, which only includes three provinces (Guangdong, Liaoning, and Sichuan) and thus lacks national representativeness.

\section{Macro and micro factors affecting individual income}

In the following, we add individual, region, and industry level explanatory variables into the model to examine the macro and micro determinants of individual income. Specifically, in model 1 , we only add individual level explanatory variables to analyze the micro effects on income; in model 2, we only include region and industry level variables to explore possible structural variations; and finally, in model 3, we fit a model that includes explanatory variables from all levels to consider both micro and macro effects simultaneously. The corresponding results for these models are shown in Table 3.

As shown in model 1 of Table 3, individual sociodemographics, human capital, and political capital are all important factors in predicting individual income. Consistent with previous findings, as the main components of human capital, education, and work experience, both have significantly positive effects on individual income. Controlling for other variables in the model, the income return from education differs substantially across gender. For each additional year of schooling, individual income increases by $7 \%$ for females but only $2 \%(=.067-.046)$ for males, which is similar to what is reported by Xie and Hannum (1996). One possible reason for this pattern is that females with little education have a much lower income than corresponding males. More working experience can also increase individual income, but this effect is marginally diminishing as indicated by a negative regression coefficient for its square term. In addition to human capital, individual sociodemographics also introduce substantive income gaps. On average, males earn a much higher income than females, and so do urban residents relative to rural residents. For males who received no education, their average income is 3.5 $[=\exp (1.253)]$ times as large as that of their female peers. If both received high school education, the gap decreases but still remains twice as large $[\exp (1.253-.046 \times 12)=$ $2.02]$ due to a higher return from education for females. ${ }^{10}$ Even after controlling for the other variables in the model, urban residents earn more than twice $[\exp (.753)=2.12]$ as much as rural residents, indicating a huge urban to rural premium. In addition, political capital still matters for individual income in contemporary China, and the average income is $23 \%$ higher $[=\exp (.205)]$ for party members than non-members. Finally, individual income is also affected by occupational status and type of work unit. Holding other things constant, each additional point on the ISEI score results in individual income increasing by about .1\%. Compared with employment by non-state/collective units, workers at state/collective owned units enjoy an advantage of about $20 \%$ $[\exp (.167)=1.18]$ in their individual income.

After including individual level covariates, the unexplained variances in model 1 decline not only for individual level residuals $\left(\sigma_{0 i}^{2}\right)$, but also for residuals $\left(\sigma_{0 j}^{2}\right.$ and $\left.\sigma_{0 k}^{2}\right)$ at the region and industry levels, as compared with the variance components results (model 0) in Table 2. This suggests that at least some of the region and industry 
Table 3 Cross-classified multilevel models for individual monthly income (Log), CFPS2010

\begin{tabular}{|c|c|c|c|}
\hline Variable & Model 1 & Model 2 & Model 3 \\
\hline \multicolumn{4}{|l|}{ Individual level } \\
\hline \multirow[t]{2}{*}{ Years of schooling } & $.067^{* * *}$ & & $.063^{* * *}$ \\
\hline & $(.008)$ & & $(.008)$ \\
\hline \multirow[t]{2}{*}{ Work experience } & $.044^{* * *}$ & & $.045^{* * *}$ \\
\hline & $(.006)$ & & $(.006)$ \\
\hline \multirow[t]{2}{*}{ Work experience square } & $-.001^{* * *}$ & & $-.001^{* * *}$ \\
\hline & $(.0001)$ & & $(.0001)$ \\
\hline \multirow[t]{2}{*}{ Male } & $1.253^{* * *}$ & & $1.256^{* * *}$ \\
\hline & $(.071)$ & & $(.071)$ \\
\hline \multirow[t]{2}{*}{ Urban resident } & $.753^{* * *}$ & & $.694^{* * *}$ \\
\hline & $(.060)$ & & $(.060)$ \\
\hline \multirow[t]{2}{*}{ Party member } & $.205^{*}$ & & $.221^{* *}$ \\
\hline & $(.082)$ & & $(.082)$ \\
\hline \multirow[t]{2}{*}{ Occupation (ISEI) } & $.009^{* * *}$ & & $.009^{* * *}$ \\
\hline & $(.002)$ & & $(.002)$ \\
\hline \multirow[t]{2}{*}{ State/collective owned work unit } & $.167^{*}$ & & $.138+$ \\
\hline & $(.075)$ & & $(.074)$ \\
\hline \multirow[t]{2}{*}{ Male $\times$ years of schooling } & $-.046^{* * *}$ & & $-.046^{* * *}$ \\
\hline & $(.008)$ & & $(.008)$ \\
\hline \multicolumn{4}{|l|}{ Region level } \\
\hline \multirow[t]{2}{*}{ GDP per capita } & & $.039^{* * *}$ & $.034^{* *}$ \\
\hline & & $(.011)$ & $(.011)$ \\
\hline \multirow[t]{2}{*}{ Average years of schooling } & & $.211^{* * *}$ & $.110^{* *}$ \\
\hline & & $(.042)$ & $(.041)$ \\
\hline \multicolumn{4}{|l|}{ Industry level } \\
\hline \multicolumn{4}{|l|}{ Industry type (reference = agriculture) } \\
\hline \multirow[t]{2}{*}{ Industry and construction } & & $5.802^{* * *}$ & $4.087^{* * *}$ \\
\hline & & $(.660)$ & $(.643)$ \\
\hline \multirow[t]{2}{*}{ Service and other } & & $5.651^{* * *}$ & $3.985^{* * *}$ \\
\hline & & $(.654)$ & $(.637)$ \\
\hline \multirow[t]{2}{*}{ Industry age } & & -.153 & .018 \\
\hline & & $(.565)$ & $(.554)$ \\
\hline \multirow[t]{2}{*}{ Industry scale } & & .033 & .008 \\
\hline & & $(.047)$ & $(.046)$ \\
\hline \multirow[t]{2}{*}{$\%$ of female employees } & & $-.684^{*}$ & .112 \\
\hline & & $(.321)$ & $(.315)$ \\
\hline \multirow[t]{2}{*}{$\%$ of employees with higher education } & & $1.036^{*}$ & .358 \\
\hline & & $(.420)$ & $(.412)$ \\
\hline \multirow[t]{2}{*}{$\%$ of state owned entities } & & $3.697^{*}$ & 1.777 \\
\hline & & $(1.648)$ & $(1.596)$ \\
\hline \multirow[t]{2}{*}{ Average revenue per capita } & & -.001 & .0002 \\
\hline & & $(.001)$ & $(.001)$ \\
\hline \multirow[t]{2}{*}{ Intercept } & $4.734^{* * *}$ & -1.685 & -1.154 \\
\hline & $(.239)$ & $(1.451)$ & $(1.419)$ \\
\hline
\end{tabular}


Table 3 Cross-classified multilevel models for individual monthly income (Log), CFPS2010 (Continued)

\begin{tabular}{lllc}
\hline Individual level residual $\left(\sigma_{0 i}\right)$ & 2.423 & 2.510 & 2.423 \\
& $(.014)$ & $(.015)$ & $(.014)$ \\
Region level residual $\left(\sigma_{0 j}\right)$ & .629 & .585 & .564 \\
& $(.043)$ & $(.040)$ & $(.039)$ \\
Industry level residual $\left(\sigma_{0 k}\right)$ & .799 & .0001 & .00002 \\
& $(.134)$ & $(.003)$ & $(.003)$ \\
\hline
\end{tabular}

Numbers in brackets are estimated standard errors. The corresponding sample sizes for individual, region and industry are $14,698,162$, and 19 , respectively $+p<.1 ;{ }^{*} p<.05 ;{ }^{* *} p<.01 ;{ }^{* * *} p<.001$

variations in income are due to different population compositions and human capital stock across regions and industries.

In model 2 of Table 3, we only include region and industry covariates to examine how social structural factors affect average individual income. At the region level, we include GDP per capita and the average years of schooling; at the industry level, we include variables indicating industry type, industry age, industry scale, the sexual and educational composition of industry employees, average revenue per capita, as well as proportion of state-owned entities representing the level of state monopoly for an industry. As seen from the estimation results, regional socioeconomic development has a beneficial effect on individual income. Controlling for other covariates in the model, an additional 10,000 yuan of county GDP per capita raises the average individual income by $4 \%$; an additional year of average education in the county leads to a more than $20 \%$ increase in average income. With respect to industry characteristics, the average income across industry types differs substantially, and compared to other employees, agricultural employees on average earn much less. This may reflect both the disadvantaged position of agriculture in China's economic structure and the seasonal fluctuation of agricultural revenue. Furthermore, the higher the proportion of female employees, the lower the average individual income; the higher the proportion of employees with higher education, the higher the average individual income; and the higher the proportion of state-owned entities in the industry, the higher the average individual income, as is consistent with Wang and Cui's (2010) finding that average income is higher in monopolized industries. In contrast, industry age, industry scale, and the average revenue per capita have no significant effect on individual income. Since model 2 does not control for individual characteristics, so the above results cannot be regarded as firm evidence of regional and industrial effects in that they can as well be a reflection of a statistical artifact due to an instance of ecological fallacy. In other words, these structural differences may result from different compositions of individual sociodemographics and human capital stock across regions and industries.

To rule out this possibility, we further estimate model 3 to include both individual and region/industry covariates simultaneously. As shown in model 3 of Table 3, the coefficients for individual covariates are essentially the same as in model 1 , so there is no need to repeat them here. At the region level, even after controlling for individual characteristics and human and political capital, the effects of county GDP per capita and average years of schooling attenuate somewhat but still remain statistically significant, indicating that the beneficial effect of regional socioeconomic development on individual income is genuine and beyond differential population compositions. At the industry 
level, however, after controlling for individual covariates, the effects of proportion of female employees, proportion of employees with higher education, and proportion of state-owned entities all become statistically insignificant. ${ }^{11}$ These results reflect that the lower average income for industries with a higher proportion of female employees may have more to do with the fact that females earn much less than males at the individual level rather than sexual "discrimination" against the whole industry. Similarly, the high average income for high technology industries (with more employees with higher education) and monopolized industries (with a higher proportion of state-owned entities) is also partly a reflection that these industries attract more individuals having better human and political capital (Zhang 2004). Therefore, it is crucial to control for the effects of individual characteristics when examining inter-industry income gaps. Nonetheless, even after controlling for a broad array of individual differences, agricultural employees still earn significantly less than employees from other industries, as indicated by the results in model 3.

\section{Macro-micro linkages for income inequality}

In the above, we examined the effects of various explanatory variables at the individual, region, and industry levels on individual income. However, it remains to be answered how different social and institutional settings (such as living in different counties or working in different industries) influence the income returns from various individual characteristics, i.e., the macro-micro linkages regarding income inequality. For example, we are interested in whether a female worker will be less discriminated against if she works in an industry dominated by female employees, whether the income return from education will be lower in an industry with a high concentration of highly educated employees, whether party membership is more important in monopolized industries, etc.

To address these questions, we add cross-level interactions into our cross-classified multilevel model. Considering that the sample size for industries is fairly small $(N=19)$ in our data, we separately add the interaction terms between region/industry covariates and individual gender, residence type, education, party membership, occupational ISEI, and type of work unit, using model 3 of Table 3 as the baseline model. The estimation results for these models are given in Table 4.

Numbers in the first column (model 4) of Table 4 show how the gender gap for individual income varies across different regions and industries. First of all, there is a significant interaction effect between county GDP per capita and gender, and an additional 10,000 yuan increase in GDP per capita reduces the gender gap for income by $2 \%$. This result is consistent with previous findings such as Hao and Li (2006), indicating that one byproduct of economic development is reducing gender inequality. Second, gender inequality in income tends to be lower in industries with more highly educated employees. One possible explanation is that these industries are likely to be high technology industries, and they may rely more on human capital and are less affected by traditional norms and practices such as gender discrimination. Third, the gender gap in income tends to be more severe in industries with more state-owned entities. This finding contradicts results from Wang and Cui (2010); further studies are necessary to better understand the issue. Last, there is no evidence that supports that 
Table 4 Cross-classified multilevel model with cross-level interactions for individual monthly income (Log), CFPS2010

\begin{tabular}{|c|c|c|c|c|c|c|}
\hline & $\begin{array}{l}\text { Male } \\
\text { (Model 4) }\end{array}$ & $\begin{array}{l}\text { Urban resident } \\
\text { (Model 5) }\end{array}$ & (Model 6) & (Model 7) & $\begin{array}{l}\text { Occupational } \\
\text { ISEl } \\
\text { (Model 8) }\end{array}$ & $\begin{array}{l}\text { State/collective } \\
\text { unit } \\
\text { (Model 9) }\end{array}$ \\
\hline \multicolumn{7}{|l|}{ Main effect } \\
\hline \multirow{2}{*}{$\begin{array}{l}\text { Main effect for each } \\
\text { column variable }\end{array}$} & .127 & .650 & $.098^{*}$ & .068 & -.002 & .289 \\
\hline & $(.404)$ & $(.484)$ & $(.044)$ & $(.645)$ & $(.014)$ & $(.479)$ \\
\hline \multirow{2}{*}{$\begin{array}{l}\text { County GDP per } \\
\text { capita }\end{array}$} & $.044^{* * *}$ & $.035^{*}$ & $.052^{* * *}$ & $.033^{* *}$ & $.041^{*}$ & $.036^{* * *}$ \\
\hline & $(.012)$ & $(.016)$ & $(.014)$ & $(.011)$ & $(.017)$ & $(.011)$ \\
\hline \multirow{2}{*}{$\begin{array}{l}\text { County average } \\
\text { education }\end{array}$} & $.103^{*}$ & $.154^{* *}$ & $.140^{*}$ & $.111^{* *}$ & $.130^{*}$ & $.126^{* *}$ \\
\hline & $(.046)$ & $(.053)$ & $(.053)$ & $(.042)$ & $(.062)$ & $(.043)$ \\
\hline \multirow{2}{*}{$\begin{array}{l}\% \text { of female } \\
\text { employees }\end{array}$} & -.702 & .222 & .776 & .121 & -1.115 & -.115 \\
\hline & $(.539)$ & $(.450)$ & $(.600)$ & $(.320)$ & $(.732)$ & $(.341)$ \\
\hline \multirow{2}{*}{$\begin{array}{l}\% \text { of employees with } \\
\text { higher } \\
\text { education }\end{array}$} & $.756+$ & .298 & -.629 & .396 & .987 & .499 \\
\hline & $(.441)$ & $(.490)$ & $(.711)$ & $(.418)$ & $(.771)$ & $(.453)$ \\
\hline \multirow{2}{*}{$\begin{array}{l}\% \text { of state-owned } \\
\text { entities }\end{array}$} & 1.048 & .533 & 1.333 & 1.687 & $-4.599^{*}$ & -.093 \\
\hline & $(1.605)$ & $(1.612)$ & $(1.629)$ & $(1.597)$ & $(2.025)$ & $(1.644)$ \\
\hline \multicolumn{7}{|c|}{$\begin{array}{l}\text { Cross-level interaction with } \\
\text { region variable }\end{array}$} \\
\hline \multirow[t]{2}{*}{ GDP per capita } & $-.019^{*}$ & -.0001 & $-.002 \dagger$ & .0004 & -.0002 & -.011 \\
\hline & $(.009)$ & $(.014)$ & $(.001)$ & $(.017)$ & $(.0003)$ & $(.010)$ \\
\hline \multirow[t]{2}{*}{ Average education } & .014 & -.044 & -.003 & .002 & -.001 & -.059 \\
\hline & $(.036)$ & $(.051)$ & $(.004)$ & $(.060)$ & $(.001)$ & $(.046)$ \\
\hline \multicolumn{7}{|l|}{$\begin{array}{l}\text { Cross-level interaction with } \\
\text { industry variable }\end{array}$} \\
\hline \multirow{2}{*}{$\begin{array}{l}\% \text { of female } \\
\text { employees }\end{array}$} & .421 & .013 & -.085 & -.335 & $.031 \dagger$ & .895 \\
\hline & $(.587)$ & $(.526)$ & $(.060)$ & $(.813)$ & $(.018)$ & $(.639)$ \\
\hline \multirow{2}{*}{$\begin{array}{l}\% \text { of employees with } \\
\text { higher } \\
\text { education }\end{array}$} & $-.656^{*}$ & .062 & $.081 \dagger$ & -.062 & -.011 & -.458 \\
\hline & $(.314)$ & $(.335)$ & $(.042)$ & $(.409)$ & $(.011)$ & $(.386)$ \\
\hline \multirow{2}{*}{$\begin{array}{l}\% \text { of state-owned } \\
\text { entities }\end{array}$} & $2.202^{* * *}$ & $1.904^{* * *}$ & $.066^{*}$ & $1.582^{* *}$ & $.164^{* * *}$ & $5.611^{* * *}$ \\
\hline & $(.251)$ & $(.278)$ & $(.030)$ & $(.508)$ & $(.030)$ & $(.884)$ \\
\hline
\end{tabular}

Numbers in brackets are estimated standard errors. The corresponding sample sizes for individual, region, and industry are $14,698,162$, and 19, respectively. These models also control for the main effects of other variables shown in model 3 of Table 3 $+p<.1 ;{ }^{*} p<.05 ;{ }^{* *} p<.01 ;{ }^{* * *} p<.001$

an increase in the percentage of female employees in an industry can reduce gender discrimination. In fact, the corresponding result suggests that the gender gap tends to be larger in industries with a higher proportion of female employees, though this effect is not statistically significant.

The second column (model 5) in Table 4 presents results for possible variations in the rural-to-urban income gap across regions and industries. These results show that the rural-to-urban income gap is nearly universal, and there is almost no significant difference by region or industry. The only exception is for employees working in industries with high proportions of state-owned entities, where urban residents enjoy a larger income advantage than rural residents do. Compared with private enterprises, state-owned enterprises are more likely to be concentrated in urban areas and tend to hold stricter requirements for their workers regarding hukou status. In fact, it is very 
difficult for rural hukou holders to obtain formal employment from state-owned entities, and this may exacerbate their already existing income disadvantage.

Similarly, the third column (model 6) in Table 4 examines how the income return from education varies according to region and industry characteristics. Firstly, there is weak evidence that the income return from education is somewhat lower in more economically developed regions than in less developed regions, but the coefficient is very small and it is only statistically significant at the $p<.1$ level. Secondly, in contrast to the so-called frog-pond effect, ${ }^{12}$ the concentration of highly educated employees in an industry does not reduce the income return from education at all. Rather, our results show that these industries tend to have a higher income return from education, which is consistent with Wang and Cui (2010). Given the same number of years of schooling, working at an industry with more highly educated employees in general returns more income. This may have something to do with the match between employment and education. In high technology industries, specialized knowledge and skills are crucial for maintaining productivity, and hence such industries are more likely to pay commensurate with training when the employee has higher education. By contrast, in traditional industries that require less specialized knowledge and skills, it is more difficult to receive a commensurate pay for highly educated individuals. Finally, model 6 also shows that the income gap between different educational groups widens as the industry becomes more monopolized, i.e., the income return from education increases as the proportion of state-owned entities in an industry increases.

The fourth column (model 7) of Table 4 shows how the income benefit for party membership varies by region and industry. Consistent with previous findings (Hao and Li 2006; Xie and Hannum 1996), the effect of party membership on individual income does not "deflate" with regional economic development and marketization, and we do not find significant regional variations. At the industry level, there is a statistically significant interaction effect between party membership and proportion of state-owned entities in an industry. As the proportion increases, the income gap between party members and non-members worsens, which may reflect the increasing importance of political capital in monopolized industries.

The fifth column (model 8) of Table 4 examines possible heterogeneity of the income gap across occupational status with respect to different regions and industries. Results show that there is no heterogeneous effect from occupation on individual income across regions. In contrast, this effect varies significantly by industry. In particular, the occupational variation of individual income increases as either the proportion of female employees or the proportion of state-owned entities increases in an industry. The latter may reflect the fact that there exist huge income gaps between managerial staff members and ordinary workers in state-owned enterprises.

The last column (model 9) of Table 4 shows how the effect of work unit on individual income varies by region and industry characteristics. Similar to what we found for place of residence and party membership, among all the region and industry factors considered here, the only significant cross-level interaction effect is for industrial monopoly (i.e., the proportion of state-owned entities in an industry). As the proportion of stateowned entities increases, the income advantage of working at state/collective units becomes even larger, suggesting that people enjoy cumulative benefits for working at monopolized sectors in monopolized industries. 


\section{Conclusion and discussion}

In this study, based on data from CFPS and region/industry statistics, we fit crossclassified multilevel models to examine the impact of labor market segmentation on income inequality in contemporary China. Our main findings are as follows:

First, both region and industry segregations are important causes of elevated income inequality, and they together account for about one fifth of the total variation in individual income. Comparatively, the impact of industry segregation is much larger than that of region segregation, and the former accounts for $14 \%$, while the latter accounts for less than $7 \%$ of total variation.

Second, region and industry factors are important determinants of average individual income. Regional economic and educational development has a beneficial effect on increasing individual income; Working at non-agricultural industries, industries with a low proportion of female employees and industries with a high proportion of highly educated employees and with a high proportion of state-owned entities all help to secure a higher average income. Even after controlling for individual gender, education, work experience, place of residence, party membership, occupation, and type of work unit, the positive effects of regional economic and educational development on individual income are still statistically significant, and non-agricultural workers have substantially higher earnings than agricultural workers as well. These findings support dual-labor market segmentation with respect to region and industry in China. That is, individual income is not only determined by individual characteristics and human capital stock, but also is affected by social and structural factors across region and industry.

Finally, we further explore the underlying mechanisms through which macro-level factors such as region and industry characteristics affect income inequality among different social groups. Our findings show that both region and industry factors affect the level of income inequality for different genders, urban and rural residents, different educational groups, party members and non-members, different occupational statuses, and different types of work unit. Especially, as the proportion of state-owned entities in an industry increases, the income gaps among various social groups widen substantially. This suggests that industrial monopoly has been a key factor that drives rising income inequality in China.

Our findings have important theoretical and practical implications for understanding the issue of income inequality in China. This study not only provides empirical evidence supporting the idea of labor market segmentation theory, but also shows the multiplicity and complexity of labor market segmentation, which offers insights by which we can further refine the current theory. Furthermore, as shown by this study, macro structures such as region and industry characteristics are important sources of widening income inequality in China. Therefore, reducing the imbalance in regional development and limiting inter-industry income gaps are both critical to our ability to narrow the large income gaps in contemporary China. In particular, policy priority should be given to how to trim industrial monopoly given that it is the singly most important structural factor that drives income inequality across different social groups. Determining how best to eliminate the status privilege associated with administrative monopoly and to restrict the rapid increases in income for high ranking managerial staff members, while simultaneously raising ordinary workers' income, should be the priority for the ongoing reform of income distribution. 
To alleviate the huge income disparity in China, it is necessary to continue and deepen the ongoing market reform, to eradicate the existing local protectionism and industry barriers, and to build up a nationally unified, open labor market that allows workers to move freely across regions and industries. At the same time, we should also be aware of the polarization effect brought by market forces. In fact, during the last several decades, many developed countries also witnessed an increase in income inequality, and such increases have caused some serious social problems such as the "Occupy Wall Street" movement in the USA (Piketty 2014; Stiglitz 2012). In other words, the market economy should be closely monitored and it is important to build up a comprehensive and effective social safety net that can help manage and control the adverse consequences of market competition.

It is worth noting that our study has some serious limitations: First, this is largely a cross-sectional study, and the findings only represent a snapshot of the income inequality issue in China and should not be extrapolated without caution. For instance, the finding that industry segregation has a larger impact on income inequality than does region segregation may not hold for other periods given that China is undergoing rapid social transformation. Second, due to data limitations, ${ }^{13}$ we base our analysis of interindustry differences on primary industrial categories rather than more detailed classifications. This may introduce some misspecification errors in our study. Moreover, given the small number of primary industrial categories, the statistical power is jeopardized for part of our analysis; for future studies, it would be helpful to utilize more detailed industrial classifications to test the robustness of our findings.

\section{Endnotes}

${ }^{1}$ According to relevant international rankings on inequality, the Gini coefficient was .473 in 2013 in China, placing it 27th among 141 countries using the available data. This coefficient is much higher than that for other major countries in the world such as the USA, Russia, Britain, and Japan. Please see https://www.cia.gov/library/publications/the-world-factbook/rankorder/2172rank.html for details.

${ }^{2}$ In total, CFPS2010 interviewed 33,600 individuals aged 16 and above. We dropped 4478 respondents who aged 65 and above, 13,577 respondents who were not in the work force, 160 respondents whose monthly income is missing, two respondents who do not report education, 106 respondents whose occupation is missing, and 579 respondents whose industry cannot be clearly classified, respectively. The final sample for our analysis is 14,698 individuals.

${ }^{3}$ According to the type of work unit reported by respondents, we treat party and government offices, public institutions, social organizations, and state or collective owned enterprises as employed in state/collective sectors, and treat all other responses as not employed in state/collective sectors.

${ }^{4}$ Due to the instance of zero values for reported monthly income, we added one into the original values before taking the log transformation.

${ }^{5}$ There are also other indicators in the CFPS county data file, such as urbanization rate and employment rate. However, preliminary analysis shows that these variables are highly correlated with country mean level of education, and for simplicity, we did not include these variables in our analysis. It is worth noting that some previous studies considered the effect of marketization level on individual income (e.g., Bian and Zhang 2002; Hao and Li 2006). 
Due to data limitations, we cannot examine this effect directly in this study. Nonetheless, previous studies indicate that regional marketization level is highly correlated with its economic development (e.g., Hao and Li report that the correlation coefficient between these two variables is larger than .7), and for this reason, GDP per capita can be regarded as an indirect indicator of level of regional marketization.

${ }^{6}$ For details about this model, please refer to Hox (2010): Chap. 9.

$$
\begin{aligned}
& { }^{7} \rho=\frac{\sigma_{0 j}{ }^{2}}{\sigma_{0 i}^{2}+\sigma_{0 j}^{2}+\sigma_{0 k}^{2}}=\frac{0.729^{2}}{2.511^{2}+0.729^{2}+1.060^{2}}=0.067 \\
& { }^{8} \rho=\frac{\sigma_{0 k}{ }^{2}}{\sigma_{0 i}{ }^{2}+\sigma_{0 j}^{2}+\sigma_{0 k}^{2}}=\frac{1.060^{2}}{2.511^{2}+0.729^{2}+1.060^{2}}=0.141
\end{aligned}
$$

${ }^{9}$ It is worth noting that the classification is more precise for regions $(N=162)$ than for industries $(N=19)$, which may have implications for comparing the relative importance of segregation by region and industry. Nevertheless, the use of primary industrial groups generally leads to more within-group heterogeneities and tends to underestimate between-industry variations, which does not change our basic conclusion that industry segregation is more important than region segregation in explaining income inequality in contemporary China.

${ }^{10}$ The estimated income gap between males and females is larger in our study than in studies by others. This is mainly due to the fact that our sample includes both urban and rural residents, while rural China has a more unequal distribution of income across gender than its urban counterpart. For instance, in our analytical sample, the average monthly income is 1079.5 yuan for rural males and 370.3 yuan for rural females, while it is 2410.8 yuan for urban males and 1594.6 yuan for urban females.

${ }^{11}$ It is worth noting that these results are not consistent with previous findings such as Wang and Cui (2010). Whether this is due to differences in sample size, variable construction, model form, or other possible reasons remains to be determined by future studies.

${ }^{12}$ That is, the same frog will look bigger if it is in a pond full of small frogs than in a pond full of big frogs.

${ }^{13}$ In CFPS2010, only primary industrial codes were released. For details, please refer to CFPS's technical report on occupational and industrial coding, available at http:// www.isss.edu.cn/cfps/d/file/wd/jsbg/2010jsbg/77efb2575f04de262ec706d7eddfefff.pdf.

\section{Funding}

This research is supported by research funding from the National Social Science Foundation of China (Project No. 13BSH016)

Authors' contributions

YQ is responsible for the overall design and writing for this study. TL made contributions for compiling the data and did preliminary analysis. Both authors read and approved the final manuscript.

Competing interests

The authors declare that they have no competing interests.

Author details

${ }^{1}$ Department of Sociology, Renmin University of China, No.59 Zhongguancun Street, Haidian District, Beijing 100872, China. ${ }^{2}$ Tianjin University, Tianjin, China.

Received: 17 August 2016 Accepted: 11 November 2016

Published online: 22 November 2016

References

Beck, E.M., P.M. Horan, and C.M. Tolbert. 1978. Stratification in a dual economy: A sectoral model of earnings determination. American Sociological Review 43(5): 704-720.

Bian, Y., and J.R. Logan. 1996. Market transition and the persistence of power: The changing stratification system in urban China. American Sociological Review 61(5): 739-758. 
Bian, Y., and Z. Zhang. 2002. Marketization and income distribution: Analyzing the 1988 and 1995 urban household income surveys. Social Science in China 5: 97-111.

Cai, F., Y. Du, and M. Wang. 2005. The Transformation and Development of China's Labor Market. Beijing: Commercial Press.

Cain, G.G. 1976. The challenge of segmented labor market theories to orthodox theory: A survey. Journal of Economic Literature 14(4): 1215-1257.

Chen, Z., G. Wan, and M. Lu. 2010. Inter-industry income inequality: An increasingly important cause of income inequality in urban China_-a regression-based decomposition. Social Science in China 3: 65-76.

Deng, F., and X. Ding. 2012. Human capital, labor market segregation and gender income gap. Sociological Studies 5: 24-46.

Dickens, W.T., and L.F. Katz. 1987. Inter-industry wage differences and industry characteristics. In Unemployment and the Structure of Labor Markets, ed. K. Lang and J. Leonard, 48-89. New York and Oxford: Blackwell.

$\mathrm{Gu}, \mathrm{Y}$., and Y. Feng. 2008. Is the industrial income distribution polarized in China? Evidence based on a nonparametric kernel density estimation. Economic Review 4: 5-13.

Guo, F., and Z. Zhang. 2012. The urban labor market status of China's floating population: A three-group approach Population Research 1: 3-14.

Hao, D., and L. Li. 2006. State monopoly and income inequality in regional disparity reform: Based on national comprehensive social survey data 2003. Social Science in China 2: 110-124.

Hox, J.J. 2010. Multilevel analysis: Techniques and applications, 2nd ed. New York, NY: Routledge.

Kalleberg, A.L., and A.B. Sorensen. 1979. The sociology of labor markets. Annual Review of Sociology 5: 351-379.

Katz, L.F., L.H. Summers, R.E. Hall, C.L. Schultz, and R.H. Topel. 1989. Industry rents: Evidence and implications. Brookings Papers on Economic Activity 1989: 209-290.

Krueger, A.B., and L.H. Summers. 1988. Efficiency wages and the inter-industry wage structure. Econometrica 56(2): 259-293.

Li, J., and Y. Gu. 2011. Hukou-based stratification in China's urban labor market. Sociological Studies 2: 48-77.

Liu, J. 2006. The change of labor market structure and returns to human capital. Sociological Studies 6: 89-119.

Liu, X., and Y. Qu. 2008. A study of wage difference among industrial enterprises in China. World Economic Papers 5: 58-76.

Luo, C., and S. Li. 2007. The human capital, the characteristics and the inequality in income of industries. Management World 10: 19-30.

Meng, X., and J. Zhang. 2001. The two-tier labor market in urban China: Occupational segregation and wage differentials between urban residents and rural migrants in Shanghai. Journal of Comparative Economics 29(3): 485-504.

Nee, V. 1989. A theory of market transition: From redistribution to markets in state socialism. American Sociological Review 54(5): 663-681.

Piketty, T. 2014. Capital in the twenty-first century. Beijing: China Citic Press.

Ren, Z., and Y. Zhou. 2009. How much does monopoly influence China's industrial income gap? Economic Theory and Economic Management 4: 25-30

Stiglitz, J.E. 2012. The price of inequality. New York: W. W. Norton \& Company.

Walder, A.G. 1992. Property rights and stratification in socialist redistributive economies. American Sociological Review 57(4): 524-539.

Walder, A.G. 1995. Local governments as industrial firms: An organizational analysis of China's transitional economy. American Journal of Sociology 101(2): 263-301.

Wang, T., and X. Cui. 2010. How does industry influence income distribution? Results of HLM analysis. Social Science in China 5: 165-180.

Wang, T., and F. Wang. 2005. Categorical sources of income inequality: The case of urban China. Sociological Studies 3: 156-181.

Wang, F., X. Zuo, and D. Ruan. 2002. Rural migrants in Shanghai: Living under the shadow of socialism. International Migration Review 36(2): 520-545.

Wu, Y. 2011. Labor market segmentation, job mobility and the two-track model of Chinese urban workers' acquisition of economic status. Social Science in China 1: 119-137.

Xie, Y., and E. Hannum. 1996. Regional variation in earnings inequality in reform-era urban China. American Journal of Sociology 101(4): 950-992.

Xie, Y., X. Zhang, J. Li, X. Yu, and Q. Ren. 2013. China Family Panel Studies 2013. Beijing: Peking University Press.

Yue, X., S. Li, and T. Sicular. 2010. Are the high salaries of employees in monopoly industries justified? Social Science in China 3: 77-93.

Zang, X. 2002. Labor market segmentation and income inequality in urban China. The Sociological Quarterly 43(1): 27-44.

Zhang, Z. 2004. Sectoral segmentation of labor markets and the labor mobility. Population Science of China 2: 45-52.

Zhang, Z. 2007. From urban-rural segmentation to regional segmentation. Population Research 6: 16-24.

Zhang, Y., and J. Chen. 2008. Human capital or industrial characteristics? An analysis of the causes of the inter-industry wage difference in China. World Economy 5: 68-80.

Zhou, X. 2000. Economic transformation and income inequality in urban China: Evidence from panel data. American Journal of Sociology 105(4): 1135-1174. 